\title{
TOAST: A VIDA DO CHEF DE COZINHA NIGEL SLATER DO LIVRO PARA O CINEMA
}

\section{TOAST: THE LIFE OF CHEF OF KITCHEN NIGEL SLATER FROM BOOK TO THE MOVIE}

SÁ, Isis Fonseca ${ }^{1}$

RESUMO: Este artigo reflete sobre a relação literatura-cinema presente na biografia do chef inglês Nigel Slater e como essas duas linguagens que tanto conversam entre si foram utilizadas para tal. O livro que deu origem ao filme foi lançado em 2003 e chama-se Toast - The Story of a Boy's Hunger. Trata-se uma autobiografia, que acompanha o período da infância até a adolescência através de pequenas cenas. $\mathrm{O}$ autor, cuja paixão pela gastronomia começou ainda na infância, se utiliza de suas memórias alimentares e afetivas como fio condutor da história. A adaptação para o cinema foi lançada sete anos depois pela BBC films, com o mesmo nome do livro. Um bom elenco conta esse livro, respeitando uma ordem cronológica e destacando os acontecimentos mais marcantes na vida do prestigiado chef.

PALAVRAS-CHAVE: Gastronomia, cinema, Nigel Slater, literatura, memória alimentar, toast.

ABSTRACT: This article reflects on the literature-cinema relationship used to tell the life story of English chef Nigel Slater and how these two languages that both talk to each other were used for such. The book that gave birth to the film was released in 2003 and is called Toast - The Story of a Boy's Hunger. It is an autobiography, which accompanies the period from childhood through adolescence through small scenes. The author, whose passion for gastronomy began as a child, uses his alimentary and affective memories as the guiding thread of history. The film adaptation was released seven years later on BBC films, with the same name as the book. A good cast tells this book respecting a chronological order and highlighting the most remarkable events in the life of the prestigious chef.

KEYWORDS: Gastronomy, cinema, Nigel Slater, literature, food memory, toast.

\footnotetext{
${ }^{1}$ Mestranda em Educação em Saúde e Ciências pelo Núcleo de Tecnologia Educacional para a Saúde da Universidade Federal do Rio de Janeiro (NUTES-UFRJ). E-mail: isisfsa@ufrj.br

Jangada | nr. 11, jan/jun, 2018 | ISSN 2317-4722 22 |P á g in a
} 


\section{INTRODUÇÃO}

No dia 28 de dezembro de 1895, em Paris, os irmãos Lumière realizaram a primeira sessão pública de projeção de imagens, na qual apresentaram dez pequenos filmes e, entre eles, aquele que pode ser considerado o primeiro filme gastronômico: intitulado Le Repas de Bébé (O Almoço do Bebê). O documentário mostra o próprio Auguste Lumière e sua mulher Marguerite, alimentando seu filho Andrée (YASOSHIMA, 2012, p. 301). Podemos afirmar então que a relação entre cinema e gastronomia nasceu há mais de um século. Atualmente, há uma grande quantidade de obras retratando a gastronomia em todos os seus aspectos e abrangendo quase todos os gêneros da sétima arte: animação, drama, comédia, documentário, etc.

Muitos filmes já foram levados ao cinema para contar a vida de chefs de cozinha consagrados. Podemos destacar entre eles Vatel, um banquete para o rei (2000) um longametragem essencialmente gastronômico, onde o renomado chef francês prepara um suntuoso banquete para Luís XIV no castelo de Chantilly. Veem-se representadas a abundância e a sofisticação da gastronomia das cortes europeias e toda engrenagem e logística por trás de cada etapa do serviço, consumo e significação da alimentação aristocrática no apogeu do absolutismo monárquico (AZAMBUJA, 2017, p. 13).

Julie \& Julia (2009) trata da história de uma aspirante a escritora e trabalhadora de escritório frustrada, que se dedica a refazer no prazo de um ano as 524 receitas do paradigmático livro de culinária clássica francesa da norte-americana Julia Child, uma das primeiras chefscelebridade (MACIEL, SABATINI, 2015, p. 7). O filme foi baseado no livro autobiográfico de mesmo nome escrito por Julie Powell.

Em Os sabores do palácio (2012) o enredo mostra a cozinheira do Palácio Presidencial francês, Hortense Laborie e a sua luta para se impor com sua cozinha camponesa num mundo da alta gastronomia (YASOSHIMA, 2012, p. 305). Hortense na verdade é a chef Danièle MazetDelpeuch, que foi a cozinheira do presidente François Mitterand por dois anos.

Há muito tempo a gastronomia se faz presente no cinema, inspirando as mais variadas tramas e frequentemente deixando de ser uma mera coadjuvante para passar a ser um dos principais elementos de algum filme. Isso não ocorre por acaso, pois é possível criar as mais diferentes histórias ao redor do mundo da culinária e dos restaurantes, mostrando afinal que a gastronomia não se restringe apenas às cozinhas. 
Toast segue a mesma linha de Julie \& Julia: é um filme baseado num livro, a autobiografia do chef inglês Nigel Slater, que cobre desde a sua infância até o fim da adolescência, acompanhando acontecimentos que vão desde a morte da mãe, passando pela descoberta da sexualidade e culminando na chegada de Nigel à Londres.

O título original do filme, Toast (torrada, em português), se refere ao que vinha a ser a refeição quando a comida a ser servida, normalmente insossa, preparada pela mãe de Nigel, se tornava intragável. A Sra. Slater não tinha nenhuma habilidade culinária e praticamente só servia comida enlatada para a família. Apesar da simplicidade, as torradas permaneceram no imaginário de Nigel de forma positiva, pois remetiam à memória afetiva da comida da mãe. $\mathrm{O}$ temperamento explosivo do pai (que não era adepto de novidades gastronômicas) torna o relacionamento com o filho difícil. As coisas mudam na vida do futuro chef quando a Sra. Potter chega para trabalhar na casa da família Slater após Nigel ficar órfão de mãe.

\section{A RELAÇÃO CINEMA-LITERATURA}

O cinema e a literatura mantém uma relação quase tão antiga quanto o próprio cinema. (SILVA, 2012, p. 181). Há inúmeros filmes baseados obras literárias, os quais podem ser mais ou menos fiéis aos livros de origem. Para Seorsi (2005) o filme, quando baseado em uma obra escrita, realiza a passagem de uma linguagem à outra, o que ocorre no intervalo entre as duas, a que chamamos de tradução. Podemos dizer então que o complexo trabalho de tradução pode ser mais ou menos literal.

Para que a tradução de uma obra literária à tela seja feita, é necessário tocar no maior número de pontos originais da obra possível, para realizar a sua narrativa dentro da compressão temporal que limita um filme. Em Toast, há a opção de contar a história de Nigel Slater respeitando uma linha do tempo, que não existe na obra literária, a qual é composta de cenas curtas que não indicam com precisão a época em que ocorreram.

Por mais que convirjam, cinema e literatura têm suas diferenças. Segundo Thais Gonçalves da Silva (2012), o cinema exerce influência maior do que a literatura uma vez que atinge um público mais numeroso e diversificado, que não precisa necessariamente excluir, como a literatura, os analfabetos, na medida que o cinema é transmitido através de imagem e som, não necessitando, na maioria das vezes, fazer uso da linguagem escrita. De acordo com Silva, deve-se levar em consideração que isso não significa que todo esse vasto público do 
cinema seja capaz de compreender ou apreciar em sua totalidade os filmes. Talvez um filme de arte tenha menos espectadores do que um best seller terá leitores.

Outro ponto de discordância entre as duas artes é a questão da autonomia: enquanto o escritor goza de maior liberdade criativa, o cinema não deixa de ser uma indústria, onde os interesses financeiros influenciam mais fortemente e a pressão por retorno comercial costuma ser maior. Isso pode fazer com que um livro sofra muitas alterações ao se transformar no roteiro de uma película, limitando a liberdade do diretor.

Contar histórias, narrar, emocionar. É isso que os livros e filmes fazem com as pessoas:

(...) cinema e literatura são escritas do nosso viver urbano, contemporâneo e se influenciam mutuamente. Obviamente, a arte literária narrativa - temos nos referido aqui à escrita - anterior ao cinema e com séculos de elaboração estilística, constitui-se como sua referência. Interessante aqui é notar o caminho inverso: a estética do cinema, aos poucos, invade a estética literária e interage com ela. (SEORSI, 2005, p. 44)

$\mathrm{O}$ ato de ler projeta significados no texto escrito. Esses significados podem estar relacionados à cultura do leitor. Por isso, não se pode impor ao filme fidelidade ou exatidão em relação ao livro, pois, não apenas o diretor lançou um olhar crítico sobre a obra e lhe deu certas interpretações, como os leitores também o fazem. Tarefa impossível seria fazer um filme exatamente igual à obra escrita, porque ninguém pode dizer o que a obra é. Todos, inclusive o autor que se transforma em leitor, têm uma visão particular da obra, e não um olhar único sobre ela.

\section{O PERSONAGEM (REAL) DO LIVRO QUE VIROU FILME}

Em sua página na internet, o chef se apresenta como um cozinheiro que escreve. Nigel Slater é um dos escritores de culinária mais amados da Grã-Bretanha. Muito antes de a gastronomia virar uma febre entre leitores e espectadores, esse talentoso cozinheiro já se dedicava à escrita culinária. Apesar de ter escrito colunas de revistas desde 1988, primeiro na Revista Marie Claire, depois para a Observer e posteriormente seus próprios livros de receitas, levou muito tempo até que ele pudesse ser persuadido a transferir suas habilidades para a televisão. Nascido em Wolverhampton, Nigel começou a cozinhar ainda jovem. Ele trabalhou em restaurantes em todo o país a partir dos 16 anos, depois mudou-se para Londres e tornou-se um testador de receitas e um cozinheiro para fotografia de alimentos. 
Seus livros de culinária ganharam uma série de prêmios, enquanto sua autobiografia Toast - A história de uma criança faminta foi adaptada pela BBC Films, estrelada por Helena Bonham Carter e Freddie Highmore.

Suas obras dividem-se em livros de culinária como Real Fast Food (publicado em 1992), Real Fast Puddings (1993), The 30- minute Cook (1994), Real Good Food (1995), Real Cooking (1997) e Real Food (1998); diários, The Kitchen Diaries (2005), The Kitchen Diaries II (2012) e The Christmas Chronicles (2017) e memórias e ensaios como Toast (2003) e Eating for England (2007).

Nigel Slater apresentou várias séries de televisão e documentários da BBC. Seus projetos atuais de incluem uma importante série de documentários. Os programas do chef são exibidos em diversos países. No mais recente deles, Nigel Slater's Middle East (exibido pelo canal inglês BBCTwo), o chef embarca em uma peregrinação ao Oriente Médio, parando primeiro no Líbano, enquanto o Ramadã chega ao fim. Mostrando uma absurda abundância de comida e generosidade, desde cafés da manhã simples de madrugada em Beirute até a gloriosa comida caseira no vale de Beqaa. O foco não é nas grandes cozinhas de badalados restaurantes, mas no que as pessoas comuns cozinham e comem.

\section{UMA AUTOBIOGRAFIA BASEADA EM MEMÓRIAS ALIMENTARES}

Nas mais diferentes sociedades, os alimentos são não apenas comidos, mas também pensados; quer dizer, a comida possui um significado simbólico - ela expressa algo mais do que apenas os nutrientes que fazem parte de sua constituição. A família também não se reproduz apenas biologicamente, mas se reproduz simbolicamente, e uma das dimensões dessa reprodução pode ser apreendida pelo modo de comer (WOORTMAN, 2013, p. 6).

Essa diferenciação entre o alimento biológico e o alimento cultural é feita por Roberto DaMatta (1986). O onde o autor estabelece uma distinção entre comida e alimento, na medida em que comida não é apenas uma substância alimentar mas é também um modo, um estilo e um jeito de alimentar-se. E o jeito de comer define não só aquilo que é ingerido, como também aquele que o ingere.

A comida desperta lembranças que permitem reconstruir a memória. Para Woortmann e Cavignac (2016), esse tipo de memória é também sensorial, marcada por cores, sensações e emoções físicas retidas. Toast - The Story of a Boy's Hunger, é um livro que utiliza as memória alimentares para contar a história pessoal do chef Nigel Slater, bem como descrever suas 


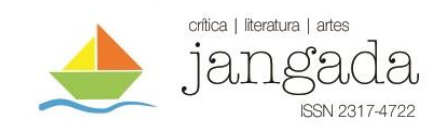

relações familiares. Para Barbara Waxman (2008), isso expressa o desejo de se reconectar com o passado através destas memórias, mesmo que o passado não tenha sido idílico, como é o caso retratado. O chef lembra com carinho e um pouco de humor sua mãe, uma mulher amorosa, mas inapta para a cozinha (ela queimou as torradas constantemente, daí seu subtítulo: a história de um garoto faminto):

Minha mãe está raspando um pedaço de torrada queimada da janela da cozinha, um sulco de aborrecimento em sua testa. Esta não é uma ocorrência ocasional. Minha mãe queima a torrada com tanta certeza quanto o sol nasce todas as manhãs. (SLATER, 2003 p. 9)

Ao fazer uso de suas memórias para escrever o livro, Slater fornece sua identidade à obra. Não se deve esquecer também que a comida é uma das mais primitivas formas de comunicação, dessa forma o chef se comunica com o leitor a partir de pratos que fizeram parte de sua vida.

Muitos dos capítulos do livro têm nome de alimentos: "Leite", "Drops de Limão", "Pato ao molho de laranja", "Bolo de aniversário", etc, ressaltando a importância da memória alimentar do autor como forma de despertar lembranças sobre acontecimentos da sua vida.

Nigel conta que sua mãe achava a preparação do jantar de domingo e das receitas de Natal uma provação exorbitante, mas o fazia de qualquer maneira por amor a ele e a seu pai. Ela morreu quando ele tinha nove anos e ele ficou emocionalmente faminto. (WAXMAN, 2008)

A fome emocional e a raiva dominam as cenas de Slater com seu pai abusivo, especialmente aquelas em que ele obriga Nigel a comer ovos para torná-lo um garoto robusto, menos frágil. Essas passagens são assim descritas:

Ele encontra formas repugnantes e incrivelmente gráficas para descrever os aspectos nojentos desses ovos. Também se lembra de ter sido repetidamente esbofeteado por seu pai quando derramou suco de framboesa no tapete novo. Ele se lembra do desprezo de seu pai quando Nigel sempre escolhia "fairy drops", sua guloseima favorita, na loja de doces. (WAXMAN, 2008 p. 375)

A virilidade de Nigel nunca atende às expectativas de seu pai, e os sentimentos de inadequação de Nigel são, ora simpaticamente, às vezes homogeneamente, retratados. As Jangada | nr. 11, jan/jun, 2018 | ISSN 2317-4722 


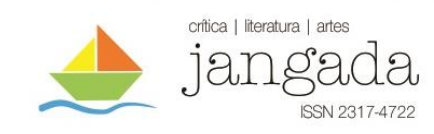

alusões do autor à sua homossexualidade e à homofobia de seu pai também sugerem a natureza tensa desse relacionamento.

Mais tarde, em sua narrativa, Slater descreve com ainda menos afeição, mas com uma dose de elogio e respeito, o requintado cozinhar de sua madrasta Joan Potter (seu pai viúvo se casa com a governanta); suas habilidades culinárias são infelizmente acompanhadas uma obsessão com a limpeza da casa, uma personalidade fria e calculista e uma constante preocupação com Nigel. Ela também é reservada sobre suas habilidades culinárias e receitas, recusando-se a compartilhá-las com o adolescente interessado. Entre Joan e o pai desaprovador, Nigel tem uma infância emocionalmente carente após a morte de sua mãe (WAXMAN, 2008).

Este livro rendeu ao chef o Prêmio Glenfiddich, que foi uma importante distinção concedida entre 1970 e 2007. Segundo Sally Gordon (2012), o renomado Glenfiddich Food \& Drink Awards celebrou a excelência na escrita, publicação e transmissão (rádio e televisão) sobre alimentos e bebidas durante mais de três décadas. Durante esse período foram agraciados os profissionais de mais alto nível e a premiação evoluiu para um grande evento reconhecido como o equivalente gastronômico do "Oscar".

De leitura fácil, com uma estrutura e linguagem simples, Toast logo se tornou um best seller e ficou por vários meses na lista dos mais vendidos. Na parte final há um glossário com várias expressões que ajudam a entender melhor o universo gastronômico particular do chef. Toast é uma obra literária que merece ser degustada (ou devorada, dependendo da voracidade do leitor).

\section{DAS PÁGINAS PARA A TELA}

Da mesma forma que a literatura foi a expressão artística de maior repercussão nos séculos XIX e XX, o cinema desponta hoje como a mais congregacional das artes, aquela que reúne o maior número de interessados (GUALDA, 2010, p. 202)

Lançado em 2010, com uma hora e meia de duração, sendo uma adaptação do livro de memórias best-seller de Nigel Slater, Toast é uma viagem nostálgica através dos comestíveis na Grã-Bretanha de 1960. O filme foi dirigido por SJ Clarkson e tem nos principais papeis Helena Bonham Carter, como a Sra. Potter, Ken Stott como o pai de Nigel, Victoria Hamilton como a mãe, Oscar Kennedy como o chef criança e Freddie Highmore como Nigel mais velho.

De acordo com Gualda, 2010: 
(...) um grande filme consiste numa história, num argumento. As grandes obras do cinema, desde sua origem, foram alternadamente adaptações e novidades. Os roteiristas seriam incapazes de descobrir, todos os anos, centenas de situações inéditas, por isso, recorrem às obras-primas da literatura ou aos livros de sucesso. A frequência com que se adaptam obras literárias para a tela faz com que o debate acerca da qualidade e mesmo da fidelidade dessas adaptações resulte em polêmicas que muitas vezes são desnecessárias e pouco produtivas. (GUALDA, 2010, p. 214)

A história parte da relação de Nigel com a gastronomia através do comportamento da Sra. Slater em relação à comida. A mãe de Nigel sempre foi uma cozinheira pobre, e sua asma crônica e a dependência de todas as comidas enlatadas também não ajudam. Nigel, por outro lado, prepara livros de receitas, dedicando todo o seu tempo a contemplar as delícias oferecidas pelos mercados de Percy Salt. À medida que a doença da mãe piora, o mesmo acontece com o relacionamento de Nigel com o pai.

Pouco antes do Natal, a Sra. Slater morre, deixando Nigel e seu pai com o coração partido. Seu pai começa a passar suas noites na loja maçônica, até que uma nova faxineira, a senhora Potter, chega ao local. Sua figura, cheia de encantos e tortas de merengue de limão, rapidamente enfeitiçaram o pai de Nigel e, para grande horror do futuro chef, os três logo embarcam em uma mudança de cidade. A única alegria de Nigel na nova escola é a aula de ciências domésticas, através da qual finalmente pode brilhar, e cozinhar logo se torna a arma chave na batalha pelo afeto de seu pai.

Ironicamente, a principal vítima dessas escaramuças culinárias é o pai de Nigel, já que sua cintura cresce à medida que a cozinha da Sra. Potter se torna obsessiva. Quando Nigel consegue um emprego na cozinha do pub local, seus olhos se abrem para um mundo de experiências, tanto culinárias quanto sexuais. Ele logo se apaixona pela comida da dona e pelo filho dela. Quando seu pai morre, Nigel arruma as malas para Londres e chega à porta do Hotel Savoy, onde começa sua carreira como chef. O filme acaba nesse ponto, ou seja, Nigel nos conta sua história pré-chef celebridade, terminando quando era só mais um jovem chegando à cidade grande em busca de um sonho.

O roteiro é inteligente ao colocar em simbolismos de cores, objetos e atos cada característica daquela família, em especialmente o relacionamento entre pai e filho. Com ares de filme francês, o filme vem carregado de métrica visual e de concepção de cenas. A fotografia 
traz curiosos focos delimitados que fazem alusão direta aos sentimentos de Nigel, como o papel de parede repleto de figuras delicadas, as flores sempre presentes nas roupas de sua mãe, os alimentos nos vestidos sempre justos da Sra. Potter (AUGUSTO, 2013).

Aparentemente leve, mas pesado e reflexivo ao revelar personagens complexos quando analisado com mais profundidade e atenção, Toast é uma deliciosa experiência cinematográfica que diverte, arranca sorrisos, emociona e nos deixa com uma vontade incontrolável de provar uma fatia de merengue de limão, que tão lindamente é retratado em close no filme.

\section{CONSIDERAÇÕES FINAIS}

Cinema e literatura andam juntos há muito tempo. Desse prolífico relacionamento, nasceu uma infinidade de obras: umas mais fiéis ao original (livro) que outras e isso não é indicativo de qualidade. É possível fazer uma leitura aproximativa entre uma obra literária e uma obra cinematográfica, já que ambas recriam um mundo ficcional e deixam ao leitor ou espectador a incumbência de também construir parte desse mundo. No presente caso, o mundo é a vida de um dos maiores escritores culinários da Inglaterra.

O chef Nigel Slater usa de sua memória alimentar afetiva para contar uma parte de sua vida. As torradas preparadas pela mãe, muitas vezes queimadas, por mais insossas e triviais que possam parecer, despertam os sentimentos mais bonitos no chef: são as lembranças do curto período que passou com sua mãe amorosa. Sua morte precoce deixou o pequeno Nigel com fome não só no sentido alimentar, mas principalmente no sentido emocional.

O merengue de limão, uma das "armas" da Sra. Potter para conquistar o pai de Nigel, por outro lado, apesar da beleza e do sabor agradável, avivam recordações de um período de sofrimento, quando uma nova mulher vem tomar o lugar de sua mãe na casa e no coração de seu pai. A competição culinária dos dois pelo amor do Sr. Slater é um ponto alto do filme.

Toast não é uma autobiografia no sentido convencional. Abrange um período entre a metade da infância e a metade da adolescência, mas nem datas nem detalhes autobiográficos são apresentados com clareza cronológica. Eventos e pessoas surgem quase ao acaso através da sequência de cenas curtas. É uma visão de criança, e depois de adolescente, de sua vida, não de um adulto que olha para trás através do prisma humanizador da experiência e da maturidade. Isso dá ao livro uma vivacidade imediata e uma terrível honestidade.

O filme respeita a ordem cronológica, mostrando os acontecimentos da vida de Nigel na medida em que vão ocorrendo. Com uma trilha sonora composta para nos fazer voltar no 
tempo, Toast vale como registro cinematográfico de uma obra literária peculiar e, com boas atuações, nos convida a conhecer a história deste grande escritor gastronômico e chef de cozinha que é Nigel Slater.

\section{REFERÊNCIAS BIBLIOGRÁFICAS}

AUGUSTO, Willian L. Crítica: Toast. Disponível em: <http://criticofilia.blogspot.com.br/2013/03/critica-toast.html >. Acesso em 09 mai. 2018.

AZAMBUJA, Luciano de. História, Gastronomia e Cinema: fontes filmes para o ensino e aprendizagem histórica. In: XXIX Simpósio Nacional de História, 2017. Anais do XXIX Simpósio Nacional de História - contra os preconceitos: história e democracia. Brasília: UNB, p. 1-18.

DA MATTA, Roberto. O que faz o brasil, Brasil? Rio de Janeiro: Rocco, 1986.

GORDON, Sally. Glenfiddich Food and drink awards. Disponível em: <http://glenfiddich.staging.tagmedia.co.uk/news-events/food-and-drink-awards/index.htmll >. Acesso em: 10 mai. 2018.

GUALDA, Linda C. Literatura e Cinema: elo e confronto. Matrizes. 3 (2): 201-220, 2010 (janjul). Disponível em: $\leq$ http://www.redalyc.org/articulo.oa?id=143016767013>. Acesso em: 13 mai. 2018.

MACIEL, Betania; SABBATINI, Marcelo. Do chef-celebridade ao \#instafood: em busca de bases teórico-metodológicas para a pesquisa em Folkgastronomia. In: XXXVIII Congresso Brasileiro de Ciências da Comunicação, 2015. Anais 2015. Rio de Janeiro: UFRJ, p. 1-15. SEORSI, Rosalia de A. Cinema na Literatura. Pro-Posições, [S.1.], v. 16, n. 2, p. 37-54, mar. 2016.

Disponível

em:

<https://periodicos.sbu.unicamp.br/ojs/index.php/proposic/article/view/8643736/11253>.

Acesso em: 11 mai. 2018.

SILVA, Thais G. da. Reflexões sobre adaptação cinematográfica de uma obra literária. Anuário de Literatura, Florianópolis, v. 17, n. 2, p. 181-201, nov. 2012. Disponível em: <https://periodicos.ufsc.br/index.php/literatura/article/view/2175-7917.2012v17n2p181>.

Acesso em: 11 mai. 2018.

SLATER, Nigel. Toast - The Story of a Boy's Hunger. Londres: Fourth Estate, 2013.

WAXMAN, Barbara F. Food Memoirs: What They Are, Why They Are Popular, and Why They Belong in the Literature Classroom College English. Vol. 70, No. 4, Special Focus: Food, p. 363-383, mar. 2008.

WOORTMANN, Ellen F. A Comida como Linguagem. Habitus, Goiânia, v. 11, n. 1, p. 5-17, nov. 2013.

Disponível

em:

<http://seer.pucgoias.edu.br/index.php/habitus/article/view/2844/1737>. Acesso em: 13 mai. 2018.

WOORTMANN, Ellen F.; CAVIGNAC, Julie A.(org). Ensaios sobre a Antropologia da alimentação: saberes, dinâmicas e patrimônios. Natal: EDUFRN, 2016. 
YASOSHIMA, José Roberto. Gastronomia na Tela: As Representações da Comida no Cinema. Revista Rosa dos Ventos, no 4(III) 300-316, jul-set, 2012 